\title{
Synaptic and Intrinsic Homeostatic Mechanisms Cooperate to Increase L2/3 Pyramidal Neuron Excitability during a Late Phase of Critical Period Plasticity
}

\author{
Mary E. Lambo and Gina G. Turrigiano \\ Department of Biology and Center for Behavioral Genomics, Brandeis University, Waltham, Massachusetts 02454
}

Visual deprivation profoundly affects visual cortical response properties, but the activity-dependent plasticity mechanisms that underlie these changes are poorly understood. Monocular deprivation (MD) induces ocular dominance (OD) shifts through biphasic changes in cortical excitability, first decreasing responsiveness to the deprived eye, and then slowly increasing responsiveness to both the deprived and spared eyes. It has been suggested that this slow gain of responsiveness is due to homeostatic synaptic scaling, but this prediction has not been tested directly. Here we show that, in rat monocular and binocular primary visual cortex (V1m and V1b), postsynaptic strength onto layer 2/3 (L2/3) pyramidal neurons is modulated in a biphasic manner by MD, first undergoing a net decrease after 1 and $2 \mathrm{~d}$ MD, increasing back to baseline after $3 \mathrm{~d}$, and finally undergoing a net potentiation between 3 and $6 \mathrm{~d}$. The time course and direction of these synaptic changes match well the known changes in visual responsiveness during OD plasticity. Viral-mediated delivery of the GluA2 C-tail in vivo blocked these synaptic changes, indicating that, like synaptic scaling in vitro, AMPA receptor trafficking via the GluA2 C-tail is required for the delayed increase in postsynaptic strength. Finally, we also observed a delayed increase in the intrinsic excitability of L2/3 pyramidal neurons following prolonged MD. These data indicate that synaptic and intrinsic homeostatic mechanisms cooperate to increase excitability of $\mathrm{L} 2 / 3$ pyramidal neurons following prolonged $\mathrm{MD}$, and suggest that these homeostatic mechanisms contribute to the delayed gain of visual responsiveness during OD plasticity.

\section{Introduction}

To function properly visual cortex requires visual experience during a well defined developmental critical period, but the cellular plasticity mechanisms that underlie this developmental refinement remain controversial. Ocular dominance (OD) shifts induced by monocular deprivation (MD) are a useful paradigm for uncovering experience-dependent plasticity rules in primary visual cortex (V1) (Hubel and Wiesel, 1970; Blasdel and Pettigrew, 1978; Drager, 1978). This process follows a biphasic time course, with a rapid decrease in responsiveness to the deprived eye followed by a slower increase in responsiveness to the open eye (Mioche and Singer, 1989; Frenkel and Bear, 2004; MrsicFlogel et al., 2007). Much evidence suggests that the initial reduction in responsiveness to the deprived eye results from a long-term depression (LTD)-like mechanism (Yoon et al., 2009), as well as plasticity of inhibitory circuitry (Sillito et al., 1980; Ramoa et al., 1988; Maffei et al., 2006, 2010). Less is known about the potentiation mechanism(s) that underlie the delayed increase

\footnotetext{
Received Sept. 21, 2012; revised March 7, 2013; accepted April 10, 2013.

Author contributions: M.E.L. and G.G.T. designed research;M.E.L. performed research;M.E.L. and G.G.T. analyzed data; M.E.L. and G.G.T. wrote the paper.

Support was provided by National Institutes of Health Grant R01 NS36853. We thank Serena David and Yasuyuki Shima for help with virus construction.

The authors declare no competing financial interests.

Correspondence should be addressed to Dr Gina G. Turrigiano, Department of Biology, MS 08, Brandeis University, 415 South Street, Waltham, MA 02454. E-mail: turrigiano@brandeis.edu.

DOI:10.1523/JNEUROSCI.4502-12.2013

Copyright $\odot 2013$ the authors $\quad 0270-6474 / 13 / 338810-10 \$ 15.00 / 0$
}

in responsiveness. In particular, it remains controversial whether this phase of OD plasticity is driven by a homosynaptic LTP-like mechanism, or a global mechanism akin to homeostatic synaptic scaling (Smith et al., 2009).

Synaptic scaling bidirectionally adjusts excitatory postsynaptic strengths to compensate for perturbations in firing, and is thought to stabilize neocortical circuit function during development and plasticity (Turrigiano et al., 1998; Turrigiano and Nelson, 2004). Recent work has suggested that synaptic scaling might contribute to OD shifts: it can be induced in the intact visual cortex by visual deprivation (Desai et al., 2002; Goel and Lee, 2007; Maffei and Turrigiano, 2008), and TNF $\alpha$ is required both for synaptic scaling up in vitro (Stellwagen and Malenka, 2006; Steinmetz and Turrigiano, 2010) and for the potentiation phase of OD plasticity (Kaneko et al., 2008). In neocortical layer $2 / 3$ (L2/3) the delayed gain of responsiveness following MD occurs for both the open and closed eyes, and in the binocular region of $\mathrm{V} 1$ during binocular deprivation $(\mathrm{BD})$, indicating that potentiation is not limited to open eye inputs (Mrsic-Flogel et al., 2007; Kaneko et al., 2008). These results strongly suggest that a homeostatic process contributes to the second phase of OD shifts in $\mathrm{L} 2 / 3$.

To test this idea directly we followed the time course of changes in excitatory postsynaptic strength, as well as intrinsic excitability, of L2/3 pyramidal neurons during MD. We found a biphasic change in postsynaptic strength, with an initial decrease after 2-3 d followed by a delayed potentiation after $6 \mathrm{~d}$. This delayed potentiation was present in both the monocular and bin- 
ocular regions of V1 (V1m and V1b) and could be induced by BD. Further, it required protein interactions with the GluA2 C-tail, a hallmark of synaptic scaling (Gainey et al., 2009). Finally, L2/3 neurons also underwent a delayed increase in intrinsic excitability between 3 and $6 \mathrm{~d} \mathrm{MD}$. Together these results suggest that the potentiation phase of OD plasticity within L2/3 is mediated by a homeostatic process in which synaptic scaling and intrinsic excitability cooperate to enhance responsiveness.

\section{Materials and Methods}

All experimental procedures used in this study were approved by the Institutional Animal Care and Use Committee at Brandeis University and followed the guidelines of the National Institutes of Health.

Lid sutures. Long-Evans rats (male and female) were anesthetized with a mixture of ketamine, xylazine, and acepromazine, and eyelids were sutured as previously described (Maffei et al., 2004). Sutures were checked each day and if not intact, animals were not used. For the sham condition, animals were anesthetized as above but did not undergo lid suture.

Slice preparation. Coronal brain slices $(300 \mu \mathrm{m})$ containing V1 were obtained as previously described (Maffei et al., 2004, 2006; Maffei and Turrigiano, 2008) using chilled $\left(1^{\circ} \mathrm{C}\right)$ modified artificial CSF (mACSF). mACSF was continuously oxygenated and contained the following (in $\mathrm{mm}$ ): 110 choline chloride, $25 \mathrm{NaHCO}_{3}, 25$ dextrose, 11.6 sodium ascorbate, $7 \mathrm{MgCl}_{2}, 3.1$ sodium pyruvate, $2.5 \mathrm{KCl}, 1.25 \mathrm{NaH}_{2} \mathrm{PO}$, and 0.5 $\mathrm{CaCl}_{2}$. Slices were cut on a Leica VT1000S vibratome and incubated on a semipermeable membrane covered by room temperature oxygenated standard ACSF containing the following (in $\mathrm{mm}$ ): $126 \mathrm{NaCl}, 3 \mathrm{KCl}, 2$ $\mathrm{MgSO}_{4}, 1.25 \mathrm{NaHPO}_{4}, 25 \mathrm{NaHCO}_{3}, 2 \mathrm{CaCl}_{2}$, and 25 Dextrose.

Electrophysiology. V1m and V1b were identified, and whole-cell patchclamp recordings obtained from layer $2 / 3$ pyramidal neurons, as previously described (Desai et al., 2002; Maffei et al., 2010; Nataraj and Turrigiano, 2011). In brief, V1m and V1b were identified using the rat brain atlas after adjusting for the lambda-bregma distance for age. The shape and morphology of the white matter were used to identify V1m and V1b. Neurons located near the center of each region were selected for recording to avoid boundary regions. Neurons were visualized with a $40 \times$ water-immersion objective using infrared-differential interference contrast optics. Internal recording solution contained (mM): $20 \mathrm{KCl}, 100$ K-gluconate, 10 HEPES, 4 Mg-ATP, $0.3 \mathrm{Na}$-GTP, 10 phosphocreatine, and $0.2 \%$ biocytin. For AMPA miniature EPSC (mEPSC) recordings, neurons were voltage-clamped to $-70 \mathrm{mV}$ in standard ACSF containing TTX $(0.2 \mu \mathrm{M})$, APV $(50 \mu \mathrm{M})$, and picrotoxin $(25 \mu \mathrm{M})$ and warmed to $33^{\circ} \mathrm{C}$. Detection criteria included amplitudes $>5 \mathrm{pA}$ and rise times $<3$ ms. $f-I$ curves were recorded in standard ACSF containing APV $(50 \mu \mathrm{M})$, DNQX $(25 \mu \mathrm{M})$, and picrotoxin $(50 \mu \mathrm{M})$ in current-clamp; a small dc bias current was injected to maintain $\mathrm{Vm}$ at $-70 \mathrm{mV}$ in between depolarizations. Neurons were not included in analyses if the resting membrane potential was more positive than $-60 \mathrm{mV}$, input resistance was $<80 \mathrm{M} \Omega$, series resistance was $>20 \mathrm{M} \Omega$, or if any of these parameters changed by $>10 \%$ during the recording. Pyramidal neurons were identified by the presence of an apical dendrite and tear-drop shaped soma and morphology was confirmed by post hoc reconstruction of biocytin fills, as described previously (Desai et al., 2002). All physiology data were analyzed using in-house programs written in IgorPro (Wavemetrics).

Virus construction and injection. The AAV-GluA2CT was generated by inserting a $154 \mathrm{bp}$ fragment encoding the GluA2 C-tail onto the end of GFP on pAAV-CMV-GFP (Stratagene). The empty vector consisted of the original pAAV-CMV-GFP. Viruses were constructed in-house and at the Vector Core facility at the University of Pennsylvania. Rats were anesthetized as above, mounted on a stereotaxic frame, and the skull was exposed. V1m or V1b were targeted by using the rat brain atlas after adjusting for the lambda-bregma distance for age. Small holes were drilled in the skull bilaterally and a glass micropipette delivered 100-800 $\mathrm{nL}$ AAV $150 \mu \mathrm{m}$ below the dural surface. The scalp was sutured and betadine was applied. Animals recovered on a heating pad and were returned to the animal facility until use.

Statistical analysis. Ns represent the number of neurons recorded; mEPSC datasets were obtained from between 3 and 8 animals for each condition, and intrinsic excitability datasets were obtained from between 2 and 4 animals for each condition. Data are presented as mean \pm SEM for the number of neurons indicated. Unpaired two-tailed Student's $t$ tests were used for pairwise comparisons. The nonparametric KolmogorovSmirnov (KS) test was used for comparing cumulative distributions. For multiple-comparisons a single factor ANOVA was used; if significant this was followed by pairwise post hoc comparisons. $p$ values $\leq 0.05$ were considered significant.

\section{Results}

MD during the critical period causes a delayed increase in responsiveness to both the deprived and nondeprived eyes (Frenkel and Bear, 2004; Mrsic-Flogel et al., 2007; Kaneko et al., 2008), but we have very little understanding of the molecular mechanisms underlying this functional change. Here we examined changes in excitatory synaptic transmission and intrinsic excitability of pyramidal neurons in $\mathrm{V} 1$ after brief or prolonged MD during the critical period for OD plasticity. All experiments were performed on acute rat visual cortical slices obtained between postnatal days 22 and 28 (p22-p28), as indicated. Whole-cell recordings and fills were obtained from visually identified pyramidal neurons from L2/3 (Desai et al., 2002; Maffei and Turrigiano, 2008). For experiments performed in V1b neurons in slices contralateral to the deprived eye (contra) were compared with those from sham-operated animals that were anesthetized but not monocularly deprived (sham), as previously described (Maffei et al., 2010). For experiments performed in V1m, neurons in slices contralateral to the deprived eye (deprived) were compared with neurons in slices ipsilateral to the deprived eye (control) from the same animal.

\section{Biphasic changes in postsynaptic strength in $\mathrm{L} 2 / 3 \mathrm{~V} 1 \mathrm{~b}$ following prolonged MD}

Previous studies have suggested that homeostatic plasticity mechanisms, such as synaptic scaling might contribute to the increased visual responsiveness to the deprived eye after prolonged MD (Mrsic-Flogel et al., 2007; Kaneko et al., 2008). We found previously that scaling up of mEPSC amplitude is induced in V1m L2/3 pyramidal neurons by $2 \mathrm{~d}$ optic nerve block (Desai et al., 2002), whereas $2 \mathrm{~d}$ of lid suture (the method generally used to induce OD shifts) reduced mEPSC amplitude (Maffei and Turrigiano, 2008). However, the impact of longer periods of lid suture on mEPSC amplitude has never been assessed. Here, we measured the amplitude, frequency, and kinetics of AMPAmediated mEPSCs as a function of different lengths of visual deprivation using monocular lid suture (MD) (Fig. 1A,B).

We began by measuring mEPSCs in L2/3 of V1b, because OD shifts are reliably produced in this area after 5-7 d of MD (Gordon and Stryker, 1996; Cang et al., 2005). Interestingly, we found that mean mEPSC amplitude was modulated in a biphasic manner by $\mathrm{MD}$ (Fig. $1 C, D$ ), first undergoing a net decrease after $1-2 \mathrm{~d} \mathrm{MD}$ (1 d sham, $n=16 ; 1$ d contra, $n=19 ; p<0.04 ; 2 \mathrm{~d}$ sham, $n=15 ; 2 \mathrm{~d}$ contra, $n=21 ; p<0.04)$, increasing back to baseline after $3 \mathrm{~d}$ ( 3 $\mathrm{d}$ sham, $n=9 ; 3 \mathrm{~d}$ contra, $n=11 ; p=0.80)$, and finally increasing above baseline between 3 and $6 \mathrm{~d}$ MD ( $6 \mathrm{~d}$ sham, $n=16 ; 6 \mathrm{~d}$ contra, $n=22 ; p<0.01)$. A similar effect was seen when the data were plotted as cumulative amplitude distributions; $2 \mathrm{~d}$ of MD shifted the distribution leftward toward smaller amplitude values (Fig. $1 F)(p<0.001$, KS test), whereas between 2 and $6 \mathrm{~d}$ MD the distribution shifted rightward toward higher amplitude values (Fig. $1 G)(p<0.001$, KS test). For this dataset (Fig. 2) and for subsequent datasets, no significant differences in mEPSC frequency or kinetics (Fig. 2D) were observed for any condition. No differences in input resistance were observed unless otherwise noted. 
Although there was no significant difference in input resistance following $2 \mathrm{~d} \mathrm{MD}$, there was a trend toward an increase after $6 \mathrm{~d} \mathrm{MD}$ (Fig. 2C); see the section on intrinsic excitability for further discussion of this trend. This trend toward increased input resistance was unlikely to have contributed significantly to the change in mEPSC amplitude observed after $6 \mathrm{~d} \mathrm{MD}$, because there was no accompanying change in mEPSC kinetics or frequency, as expected if the increase in mEPSC amplitude was due to an improved space clamp (Rall and Segev, 1985; Spruston et al., 1993). Further, neither mEPSC amplitudes nor rise times were correlated with input resistance for either the $6 \mathrm{~d}$ sham or MD condition ( $6 \mathrm{~d}$ sham amplitude, $R^{2}=0.026$; rise time, $R^{2}=0.029$; $6 \mathrm{~d}$ MD amplitude, $R^{2}=0.015$; rise time, $R^{2}=0.009$ ) (Fig. 2E). Together, these data demonstrate a biphasic response of mEPSC amplitude to MD, with an initial decrease in postsynaptic strength, followed by a potentiation of postsynaptic strength after prolonged MD.

Like many forms of experiencedependent plasticity, the ability of synapses to express synaptic scaling up is developmentally regulated (Desai et al., 2002). This raised the possibility that developmental timing, rather than length of deprivation, was responsible for the lack of effect of $3 \mathrm{~d}$ MD between p21 and p24. To control for this possibility we performed $3 \mathrm{~d}$ of $\mathrm{MD}$ from p24 to p27, to coincide with the end of the $6 \mathrm{~d} \mathrm{MD}$ above (Fig. 1A). Like the earlier $3 \mathrm{~d} \mathrm{MD}$, this manipulation had no impact on mEPSC amplitude ( $3 \mathrm{~d}$ sham, $n=12 ; 3 \mathrm{~d}$ contra, $n=12 ; p=0.66$ ) (Fig. $1 E$ ). Thus the delayed potentiation during $\mathrm{MD}$ is not an artifact of developmental regulation of synaptic scaling, but instead likely reflects a time-dependent interplay between a depressive and potentiating process.

\section{Postsynaptic strengths in $\mathrm{V} 1 \mathrm{~m}$ and $\mathrm{V} 1 \mathrm{~b}$ respond in a similar time-dependent manner to MD}

The binocular and monocular regions of V1 are thought to have similar intracortical connectivity and neural plasticity mechanisms, and differ mainly by the presence or absence of competitive inputs from the two eyes. Brief MD causes reduced visual responsiveness in both $\mathrm{V} 1 \mathrm{~b}$ and $\mathrm{V} 1 \mathrm{~m}$, while prolonged $\mathrm{MD}$ causes increased responsiveness in both areas (Mrsic-Flogel et al., 2007; Kaneko et al., 2008). To test whether the effects of MD on excitatory postsynaptic strengths are similar between $\mathrm{V} 1 \mathrm{~b}$ and $\mathrm{V} 1 \mathrm{~m}$, we measured mEPSCs in V1m L2/3 pyramidal neurons after different periods of MD.

Similar to V1b, 1 and $2 \mathrm{~d}$ of MD caused a reduction in $\mathrm{mEPSC}$ amplitude in V1m ( $1 \mathrm{~d}$ control, $n=17 ; 1 \mathrm{~d}$ deprived, $n=18 ; p<$ 0.04; 2 d control, $n=14 ; 2$ d deprived, $n=15 ; p<0.01)$, $3 \mathrm{~d}$ MD produced no net change ( $3 \mathrm{~d}$ control, $n=28 ; 3 \mathrm{~d}$ deprived, $n=$
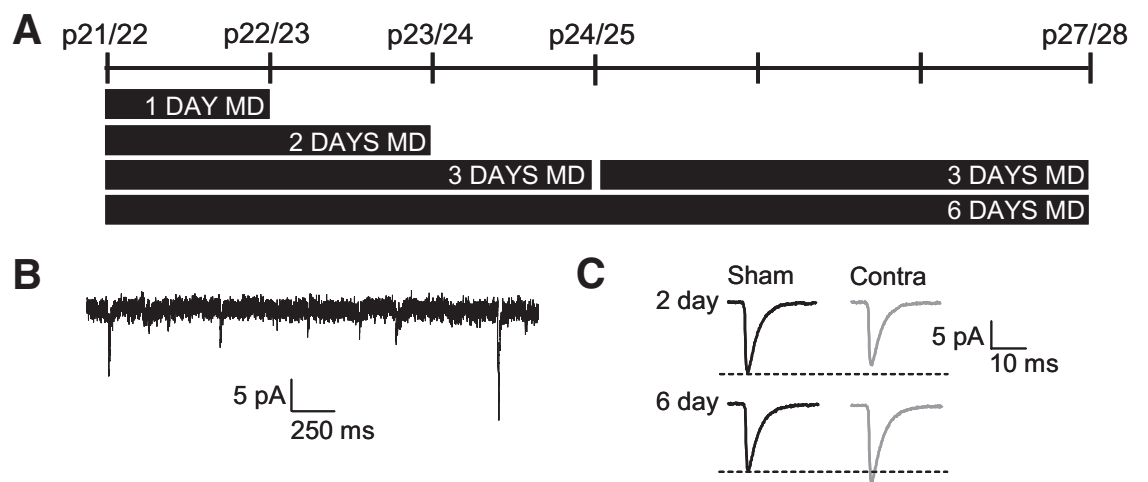

E

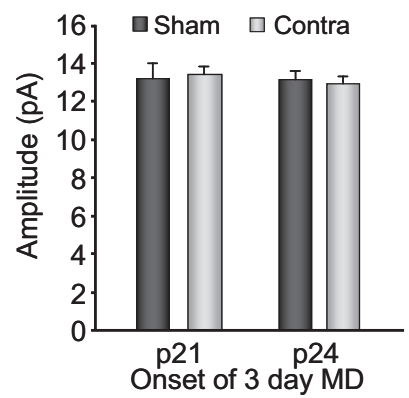

G

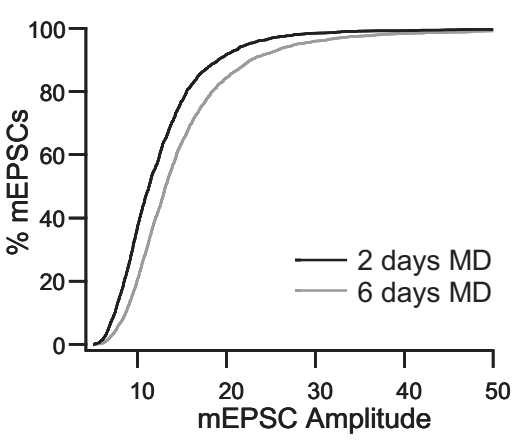

Figure 1. Biphasic changes in mEPSC amplitude onto $L 2 / 3$ pyramidal neurons during MD in V1b. $A$, Timeline of visual deprivation paradigm. $\boldsymbol{B}$, Representative whole-cell voltage-clamp recording of mEPSCs from a pyramidal neuron in L2/3. $\boldsymbol{C}$, Average mEPSC waveCumulative distributions for $2 \mathrm{~d}$ contra and $6 \mathrm{~d}$ contra conditions. ${ }^{*} p<0.05$ here and in subsequent figures.

$26 ; p=0.23)$, and $6 \mathrm{~d}$ MD caused an increase in mEPSC amplitude ( 6 d control, $n=20 ; 6$ d deprived, $n=27 ; p<0.01$ ) (Fig. $3 A, B)$. Also consistent with our finding in V1b, no significant differences were observed in access and input resistances, mEPSC rise time and decay, or mEPSC frequency (Fig. $3 C$ ). Thus in both regions of $\mathrm{V} 1 \mathrm{mEPSC}$ amplitude onto L2/3 pyramidal neurons undergo biphasic changes in response to $\mathrm{MD}$, with an initial decrease in postsynaptic strength followed by a slower increase in postsynaptic strength. The time course and direction of these changes in mEPSC amplitude match the changes observed in visual responsiveness during OD plasticity (Frenkel and Bear, 2004; MrsicFlogel et al., 2007), suggesting that they contribute to the initial loss of responsiveness to the deprived eye, and the delayed increase in responsiveness to both eyes.

Binocular deprivation reveals mechanistic differences between V1b and V1m

Due to the nature of visual cortical circuitry, MD will reduce and blur all sensory drive to $\mathrm{V} 1 \mathrm{~m}$, whereas $\mathrm{V} 1 \mathrm{~b}$ still receives intact 

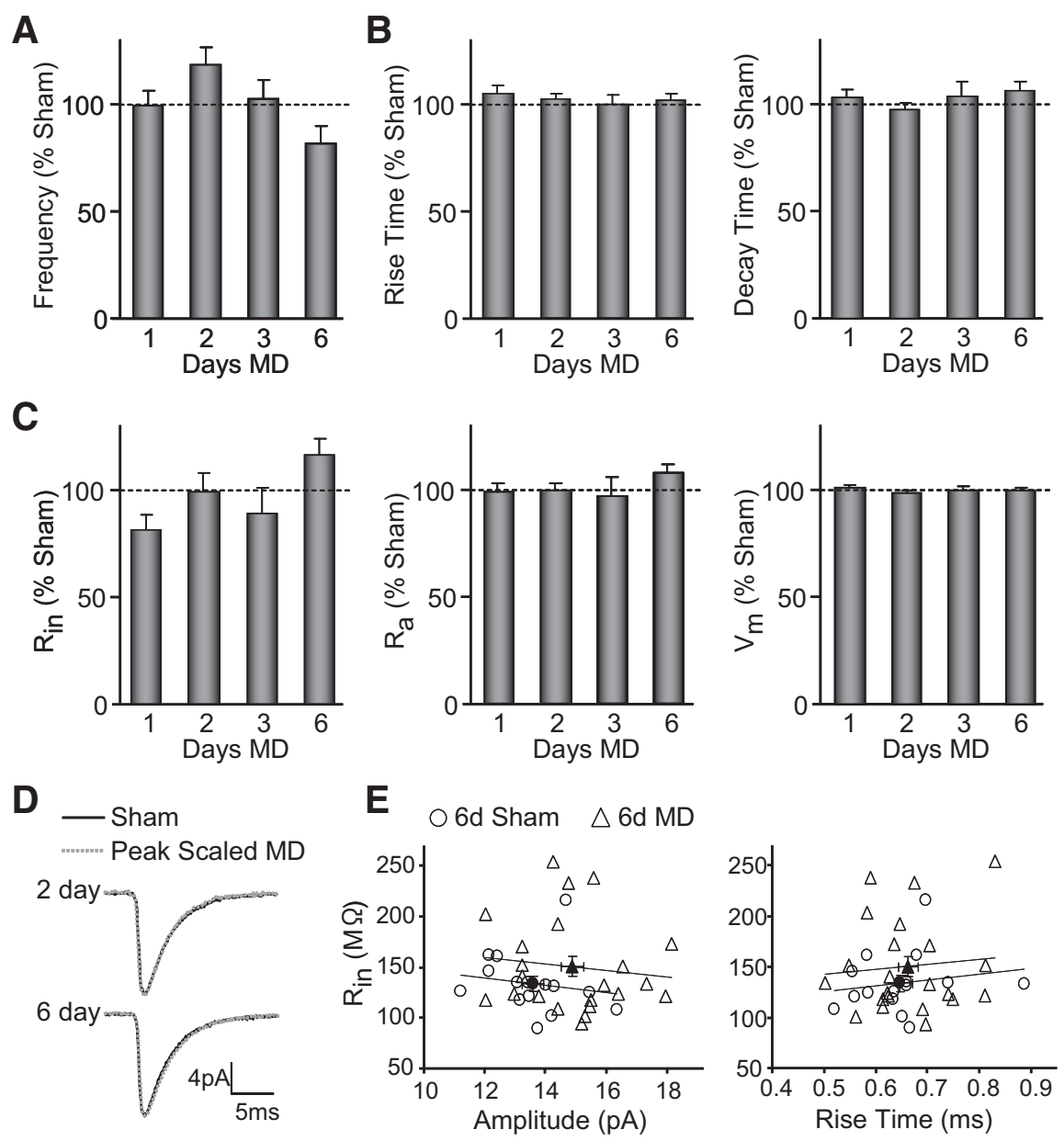

Figure 2. MD does not significantly affect mEPSC frequency, $\mathrm{mEPSC}$ kinetics, or passive neuronal properties in $\mathrm{V} 1 \mathrm{~b}$. $A$, Average $\mathrm{mEPSC}$ frequency. $\boldsymbol{B}$, Average mEPSC rise and decay times. $\boldsymbol{C}$, Input resistance (Rin), access resistance (Ra), and resting membrane potential $\left(V_{m}\right)$ after $1,2,3$, or $6 \mathrm{~d}$ MD. Data are presented as a percentage of the age-matched sham condition. $\boldsymbol{D}$, Sham and peak scaled MD average mEPSC waveforms after 2 and $6 \mathrm{~d}$. E, mEPSC amplitude (left) and rise time (right) plotted against Rin after $6 \mathrm{~d}$ sham (circles) and MD (triangles). Individual cells are plotted as open points and averages for each condition are closed points. Linear best-fit for each condition shown in solid lines.
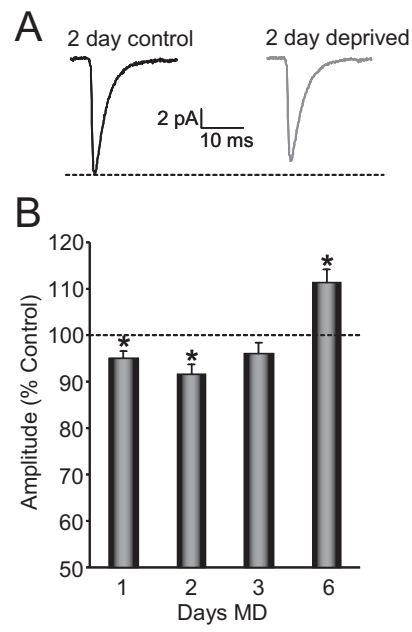

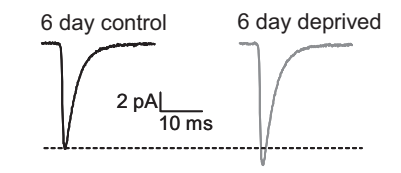

C

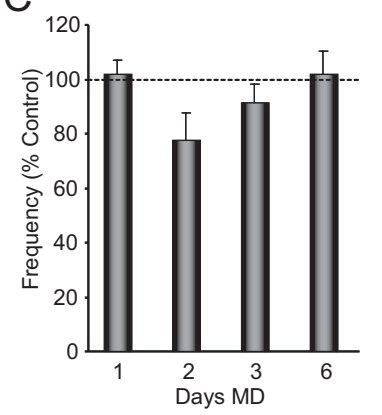

Figure 3. Biphasic changes in mEPSC amplitude during MD in V1m. $\boldsymbol{A}$, Average mEPSC waveforms for 2 and $6 \mathrm{~d} \mathrm{MD}$ conditions and matched controls from the nondeprived hemisphere. $\boldsymbol{B}$, Average mEPSC amplitude computed for each neuron and then averaged for each condition. Data are presented as a percentage of the control condition. C, Average mEPSC frequency presented as a percentage of the control condition. input through the open eye (Antonini et al., 1999). If the increase in mEPSC amplitude after prolonged MD is a homeostatic response to reduced sensory drive, then it should be induced in V1b after either monocular or binocular lid suture (BD). In contrast, if this mechanism relies on competition between the two eyes then BD should not induce a delayed potentiation. To test whether spared input through the open eye was required to produce any of the effects on mEPSC amplitude observed in V1b we performed BD for 2, 3, and $6 \mathrm{~d}$ and measured mEPSCs. In $\mathrm{V} 1 \mathrm{~b}, 6 \mathrm{~d} \mathrm{BD}$ produced a net increase of mEPSC amplitude comparable to that induced by MD ( $6 \mathrm{~d}$ sham, $n=16 ; 6 \mathrm{~d} \mathrm{BD}$, $n=25 ; p<0.03$ ) (Fig. $4 A$ ), providing support for the interpretation that this increase is due to homeostatic synaptic scaling.

We next tested the effects of shorter periods of $\mathrm{BD}$ in $\mathrm{V} 1 \mathrm{~b}$, expecting that this would reduce $m E P S C$ amplitude as for $2 \mathrm{~d}$ MD (Figs. $1 C, D, 3 A, B$ ). To our surprise, 2 and $3 \mathrm{~d}$ BD produced no change in mEPSC amplitude in V1b ( $2 \mathrm{~d}$ sham, $n=$ $15 ; 2 \mathrm{~d} \mathrm{BD}, n=27 ; p=0.56 ; 3 \mathrm{~d}$ sham, $n=$ 9; $3 \mathrm{~d} \mathrm{BD}, n=17 ; p=0.99$ ) (Fig. $4 A$ ), indicating that, in $\mathrm{V} 1 \mathrm{~b}$, spared-eye input is required for the reduction in $\mathrm{mEPSC}$ amplitude induced by $2 \mathrm{~d}$ MD. This result strongly suggests that the plasticity mechanisms underlying the reduction in mEPSC amplitude differ between V1b and $\mathrm{V} 1 \mathrm{~m}$, because in the former they require spared-eye input, whereas in the later they do not. An alternative explanation, which challenges conventional theory, is that $\mathrm{V} 1 \mathrm{~m}$ is receiving some sensory input through the open (ipsilateral) eye during $\mathrm{MD}$, and the depressive mechanism is competitive in both cases. If so, the prediction is that brief $\mathrm{BD}$ should produce no change in $\mathrm{mEPSC}$ amplitude in V1m. When this prediction was tested, we found that $2 \mathrm{~d}$ of BD decreased mEPSC amplitude in V1m to the same degree as MD, ruling out this possibility ( $2 \mathrm{~d}$ control, $n=14 ; 2 \mathrm{~d}$ $\mathrm{BD}, n=15 ; p<0.001$ ) (Fig. $4 B$ ). Thus in V1b depression of mEPSC amplitude requires spared eye input, whereas in V1m it does not.

\section{Prolonged visual deprivation increases intrinsic excitability of V1b L2/3 pyramidal neurons}

Like synaptic strength, the intrinsic excitability of neurons can be homeostatically regulated to counter perturbations in drive (Turrigiano et al., 1994; Desai et al., 1999; Marder and Goaillard, 2006; Maffei and Turrigiano, 2008). We wondered whether, in addition to synaptic changes, brief and/or prolonged MD might also induce changes in intrinsic excitability of L2/3 pyramidal neurons in V1b. To assess changes in intrinsic excitability, we measured the frequency of action potential firing in response to steps of depolarizing direct current ( $f-I$ curves), in the presence of pharmacological blockers of synaptic transmission. There was no significant change in the $f-I$ curves after 1,2 , or $3 \mathrm{~d}$ MD (Fig. 
$5 A)$. In contrast, after $6 \mathrm{~d} \mathrm{MD}$ there was a pronounced leftward shift in the $f-I$ curve ( $6 \mathrm{~d}$ sham, $n=16 ; 6 \mathrm{~d}$ contra, $n=17$ ) (Fig. $5 A, B$ ), and a significant decrease in current threshold for evoking action potentials (measured with $10 \mathrm{pA}$ current steps around threshold, $p<0.01$ ) (Fig. 5C). The leftward shift of the $f-I$ curve and reduced current threshold indicate an increase in intrinsic excitability, which was accompanied by an increase in input resistance $(p<0.01)$ (Fig. $5 C$ ). Although the trend toward increased input resistance following MD was not significant in our mEPSC recordings (Figs. $2 C, 8 F$ ), when all of the $6 \mathrm{~d}$ MD input resistance data were combined (from all mEPSC and $f-I$ recordings in V1b) there was a significant, $\sim 30 \%$ increase in input resistance $(p<0.01)$.

Next, we tested the effects of prolonged BD on intrinsic excitability. Like MD, $6 \mathrm{~d}$ BD also produced a shift in the $f-I$ curve to the left (Fig. $5 A, B)$, a decrease in current threshold ( $6 \mathrm{~d}$ sham, $n=16 ; 6 \mathrm{~d} \mathrm{BD}, n=12 ; p<0.04)$, and an increase in input resistance $(p<0.05)$ (Fig. $5 C$ ). Interestingly, the $f-I$ curve after BD only shifted to the left at low current injections and was similar to the sham condition at high current injections. This result raises the possibility that different conductances are affected by prolonged $\mathrm{MD}$ and $\mathrm{BD}$; however, both deprivation methods induce a homeostatic increase of intrinsic excitability. In the context of OD shifts, these data suggest that intrinsic plasticity of excitatory neurons is likely not contributing to the initial reduction in responsiveness to the deprived eye, but a homeostatic increase of intrinsic excitability along with synaptic scaling up may cooperate to boost responsiveness to both the deprived and nondeprived eye inputs following prolonged MD.

Intrinsic excitability of L2/3 pyramidal neurons is strongly developmentally regulated, and decreases between p21 and p28, with the largest decrease occurring between p23 and p24 (Fig. 6A). In addition to a significant increase in current threshold, input resistance also decreased with development (ANOVA, threshold: $p<0.01$; Rin: $p<0.03$ ) (Fig. $6 B$ ). This raises the possibility that the increase of intrinsic excitability after $6 \mathrm{~d}$ MD reflects an experience-dependent developmental delay, rather than a true increase from baseline. To examine this we overlaid the $f-I$ curves from sham $\mathrm{p} 24, \mathrm{MD}$ p24, sham p27, and MD p27 (Fig. 6C). This analysis reveals that at p24 intrinsic excitability has undergone the normal developmental decrease with or without $3 \mathrm{~d} \mathrm{MD}$, and after another $3 \mathrm{~d}$ of MD excitability increases again relative to both the p24 and the p27 baseline (Fig. $6 C$ ). Thus MD between p24 and p27 increases intrinsic excitability rather than preventing a developmental decrease.

\section{The GluA2 C-tail is required for changes in postsynaptic strength in $\mathrm{V} 1 \mathrm{~b}$}

It is well established that synaptic scaling in vitro is accomplished through changes in the accumulation of GluA2-containing
A

B inocular V1

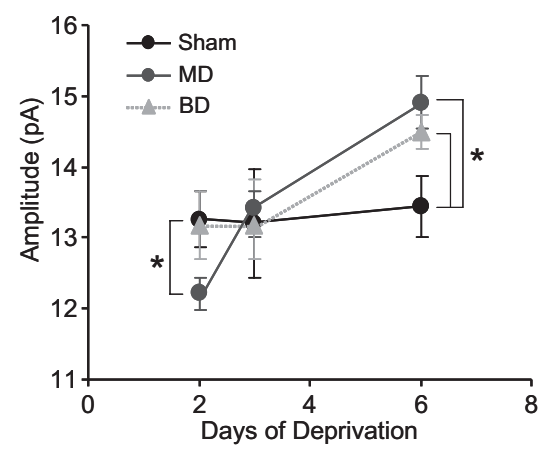

B Monocular V1

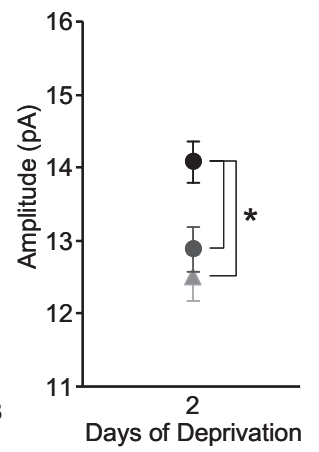

Figure 4. Effects of binocular deprivation in V1b and V1m. $A$, Average mEPSC amplitude in sham (black), MD (gray circles), and BD (gray triangles) conditions for 2, 3, and $6 \mathrm{~d}$ deprivation in V1b. $\boldsymbol{B}$, Control (black), MD (gray circles), and BD (gray triangles) conditions for $2 \mathrm{~d}$ deprivation in V1m.
A
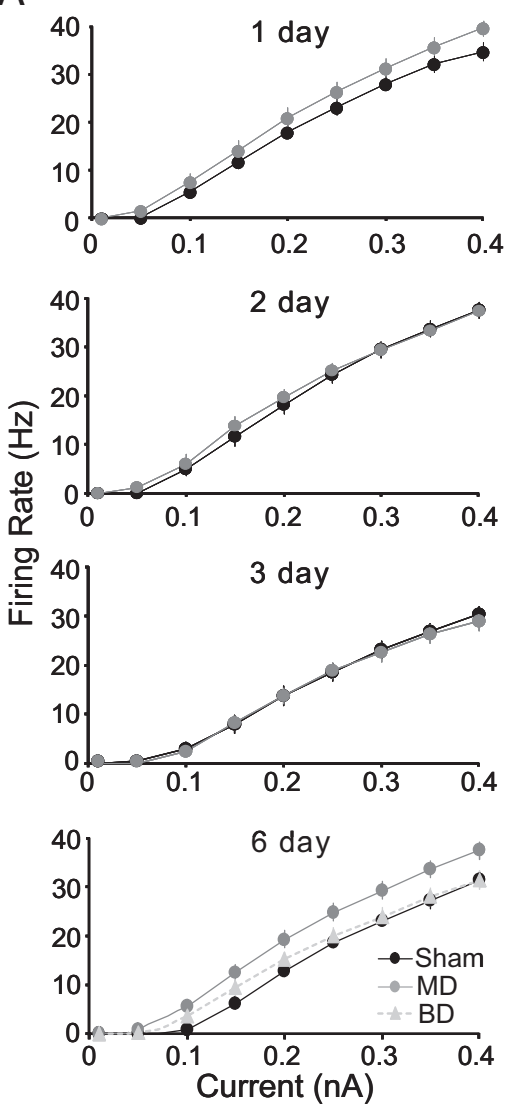

Figure 5. Prolonged but not brief $M D$ increases intrinsic excitability of $L 2 / 3$ pyramidal neurons in $V 1 b$. $A$, Average $f-I$ curves for sham (black circles), MD (gray circles), and BD (gray triangles) conditions after 1, 2, 3, and $6 \mathrm{~d}$ of deprivation. $\boldsymbol{B}$, Examples of evoked responses (top to bottom) of neurons from sham, $\mathrm{MD}$, and BD conditions after $6 \mathrm{~d}$ of deprivation. $C$, Average values (top to bottom) of current threshold, input resistance, and resting membrane potential in control (black), MD (gray), and BD (white) conditions in layer 2/3 V1b after $6 \mathrm{~d} M D$.
B

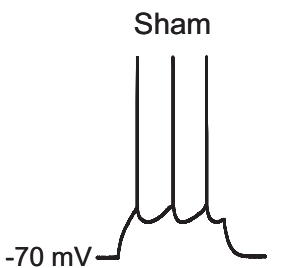

$20 \mathrm{mV}$
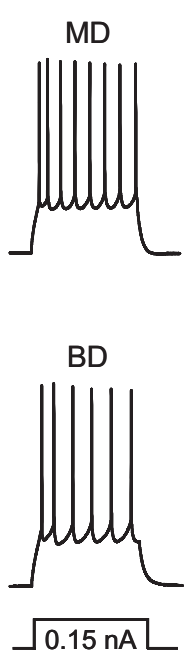

C asham $\square \mathrm{MD} \square \mathrm{BD}$

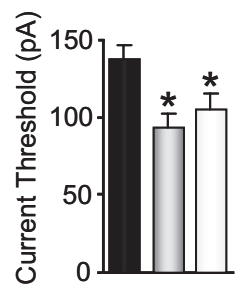

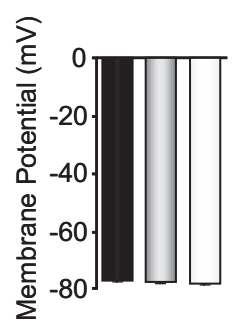

AMPA receptors at the postsynaptic membrane (O'Brien et al., 1998; Wierenga et al., 2005; Goold and Nicoll, 2010), through a process that requires interactions with the GluA2 C-tail and can be prevented by knockdown or knock-out of GluA2, or by expressing the GluA2 C-tail fragment (Gainey et al., 2009; Goold and Nicoll, 2010). In contrast, the other form of synaptic plasticity postulated to underlie the slow potentiation of responses fol- 
A

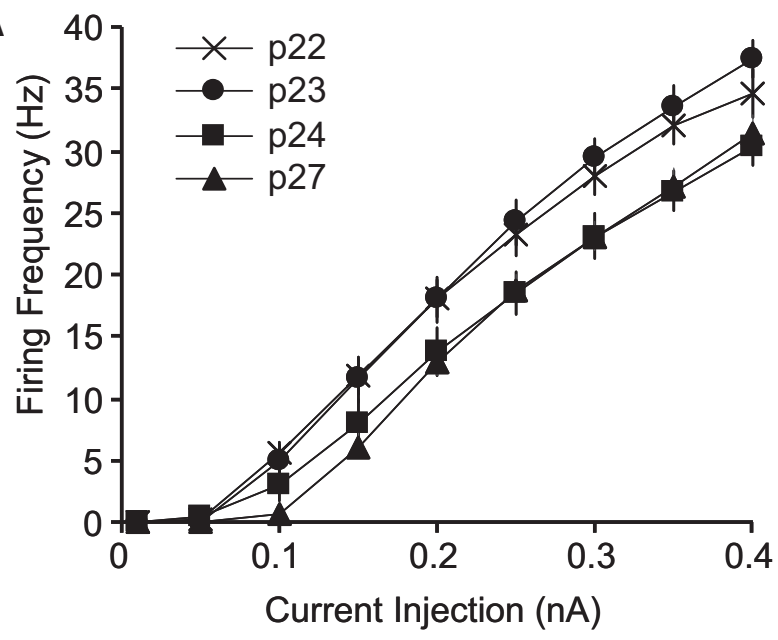

B

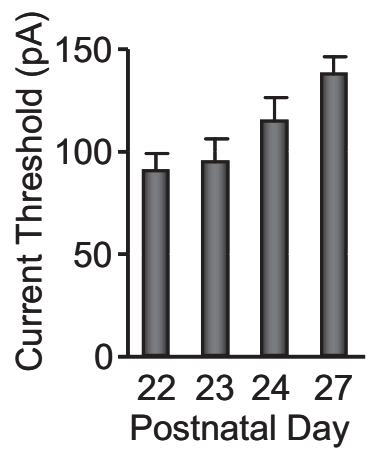

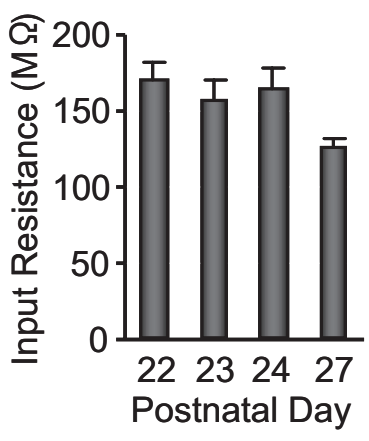

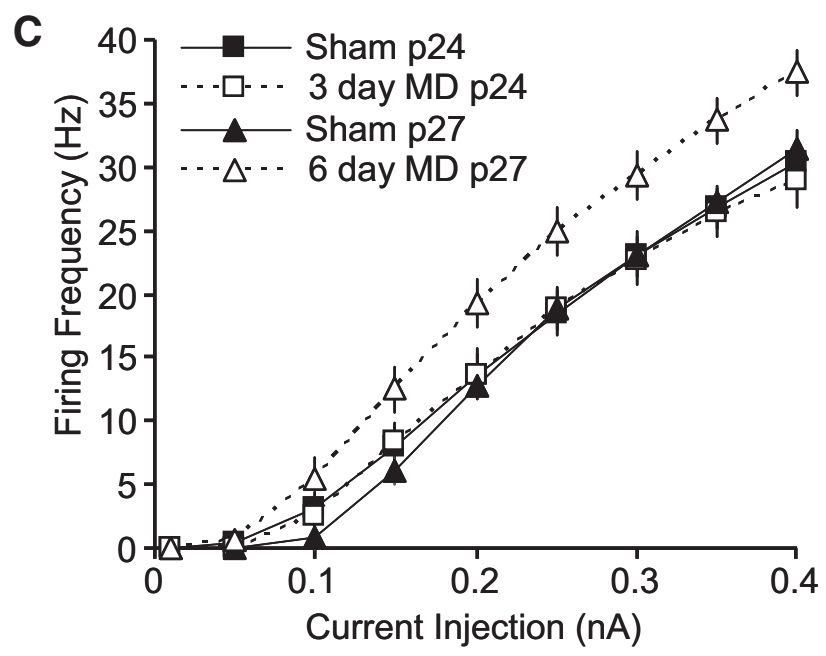

Figure 6. Intrinsic excitability decreases with development in V1b. A, Average $f-I$ curves for sham conditions on postnatal days $22,23,24$, and 27 . $\boldsymbol{B}$, Developmental changes in current threshold ( $p<0.01$, ANOVA) and Rin ( $p<0.03$, ANOVA) for sham conditions. C, Average $f-I$ curves for sham and MD conditions after 3 and $6 \mathrm{~d}$ of deprivation.

lowing MD, NMDA-receptor-dependent LTP, does not depend on GluA2 C-tail interactions (Jia et al., 1996; Malenka and Bear, 2004; Gainey et al., 2009; Granger et al., 2013). GluA2-dependent trafficking is also required for the expression of some forms of LTD (Lee et al., 2002; Yoon et al., 2009).

To determine whether the changes in MEPSC amplitude induced by prolonged $\mathrm{MD}$ in vivo require GluA2 C-tail interactions, we used an adeno-associated viral vector (AAV) to deliver either the GluA2 C-tail or an empty vector (EV) control virus (along with GFP) to neurons in L2/3 V1. Depending on the distance of the slice from the injection site the percentage of infected neurons ranged from 15-65\%, allowing us to record from infected and nearby noninfected pyramidal neurons from the same slices (Fig. $7 A, B$ ).

To verify that viral injection and infection alone had no impact on mEPSC amplitude or the ability of synapses to undergo experience-dependent changes, we began by infecting neurons with the EV with or without MD. EV was delivered to L2/3 V1b on p16-18, MD was performed 4-5 d later on p21/22, and mEPSC recordings were obtained from infected and uninfected neurons from sham or contralateral hemispheres on p27/28. Infection with the EV had no significant impact on baseline mEPSC amplitude compared with uninfected controls ( $6 \mathrm{~d}$ sham uninfected, $n=8 ; 6 \mathrm{~d}$ sham EV, $n=6 ; p=0.76$ ) (Fig. $7 C$ ) or on input resistance or resting membrane potential (Fig. $7 D$ ). In the contralateral hemisphere, $6 \mathrm{~d}$ MD significantly increased mEPSC amplitude in both uninfected and EV infected neurons ( $6 \mathrm{~d}$ contra uninfected, $n=15 ; p<0.01 ; 6 \mathrm{~d}$ contra EV, $n=6 ; p<0.05)$ (Fig. 7C), indicating that infection with the EV does not impair the ability of neurons to undergo plasticity. In a separate set of experiments, we determined that shorter periods of infection with the AAV EV (6 d) also had no impact on baseline synaptic or cellular properties, or on MD-induced plasticity (data not shown).

Next, the GluA2 C-tail containing AAV was injected into L2/3 V1b 4-5 d before the start of visual deprivation and mEPSCs were measured from uninfected and infected neurons after 2 or $6 \mathrm{~d}$ of MD (Figs. 7B, 8A). Expression of the virus did not affect baseline mEPSC amplitude in the sham hemisphere at either time point ( $2 \mathrm{~d}$ sham uninfected, $n=7 ; 2 \mathrm{~d}$ sham infected, $n=12 ; p=$ 0.29; $6 \mathrm{~d}$ sham uninfected, $n=8 ; 6 \mathrm{~d}$ sham infected, $n=8 ; p=$ 0.93 ) (Fig. $8 B, E$ ). In the contralateral condition there was no change in mEPSC amplitude after $2 \mathrm{~d}$ MD in neurons expressing the GluA2 C-tail ( $2 \mathrm{~d}$ sham, $n=19 ; 2 \mathrm{~d}$ contra infected, $n=12$; $p=0.77)$, whereas uninfected neurons showed a decrease in mEPSC amplitude similar to that seen in control animals $(2 \mathrm{~d}$ sham, $n=19 ; 2 \mathrm{~d}$ contra uninfected, $n=8 ; p<0.03$ ) (Fig. $8 B, D)$. This result indicates that protein interactions with the GluA2 $\mathrm{C}$-tail are required for the reduction in MEPSC amplitude induced by $2 \mathrm{~d} \mathrm{MD}$, suggesting that this change is driven by a GluA2-dependent form of synaptic depression.

Interestingly, viral infection had a transient impact on input resistance. Input resistance of infected neurons was reduced in both the sham and deprived conditions after $7 \mathrm{~d}$ of infection $(2 \mathrm{~d}$ post-MD, $2 \mathrm{~d}$ sham uninfected, $n=7 ; 2 \mathrm{~d}$ sham infected, $n=12$; $p=0.06 ; 2$ d contra uninfected, $n=8 ; 2$ d contra infected, $n=12$; $p<0.02)$, but recovered by $11 \mathrm{~d}$ postinfection $(6 \mathrm{~d}$ post-MD) (Fig. 8C,F). Given that mEPSC amplitude (Fig. $8 B$ ) and kinetics (data not shown) were not impacted by this drop in input resistance it is unlikely that our ability to measure mEPSCs was significantly impacted.

The GluA2 C-tail was also able to block the increase in mEPSC amplitude induced by $6 \mathrm{~d}$ MD. Whereas mEPSC amplitude of uninfected neurons in the contralateral hemisphere increased as expected ( $6 \mathrm{~d}$ sham, $n=22 ; 6 \mathrm{~d}$ contra uninfected, $n=15 ; p<$ $0.01)$, mEPSCs from infected neurons did not. In fact, mEPSC amplitude was reduced to levels below the sham condition $(6 \mathrm{~d}$ sham, $n=22 ; 6 \mathrm{~d}$ contra infected, $n=6 ; p<0.03$ ) (Fig. $8 E, G$ ). This result is consistent with the interpretation that prolonged MD induces homeostatic synaptic scaling up that relies on GluA2 $\mathrm{C}$-tail interactions. Further, the experience-dependent reduction in mEPSC amplitude below control values in GluA2 C-tail ex- 
pressing neurons suggests that block of scaling up unmasks a slow, non-GluA2mediated form of depression that occurs simultaneously during prolonged MD. These data make it clear that MD induces multiple, temporally overlapping forms of synaptic plasticity in L2/3 pyramidal neurons.

\section{Discussion}

Despite decades of effort, the cellular mechanisms underlying OD shifts remain controversial. In particular, the mechanism(s) that underlie the potentiation phase of OD plasticity have been attributed either to homosynaptic LTP, or to a global homeostatic process akin to synaptic scaling, with little direct evidence for either theory. Here we ask whether synaptic scaling is induced at synapses onto L2/3 pyramidal neurons during the potentiation phase of OD plasticity. We show that prolonged MD induces biphasic changes in mEPSC amplitude, with an initial depression after $1-2 \mathrm{~d}$ followed by a potentiation between 2 and $6 \mathrm{~d}$. The delayed mEPSC potentiation relied critically on GluA2 C-tail interactions, and could be induced by both MD and BD, as expected for global synaptic scaling. Intrinsic excitability increased in parallel with the increase in mEPSC amplitude, suggesting that intrinsic and synaptic homeostatic mechanisms contribute synergistically to delayed response potentiation. The biphasic time course of these effects during MD closely match the changes in visual responsiveness that have been documented previously (Mioche and Singer, 1989; Frenkel and Bear, 2004), suggesting that global homeostatic mechanisms make an important contribution to the delayed potentiation phase of OD plasticity within L2/3.

There is considerable evidence that LTD of excitatory synaptic connections contributes to the first (depressive) phase of OD shifts. Brief MD reduces the magnitude of unitary excitatory connections onto L2/3 pyramidal neurons (Maffei and Turrigiano, 2008) and occludes the further induction of LTD (Crozier et al., 2007). Consistent with these earlier reports we find that 1 or $2 \mathrm{~d}$ of $\mathrm{MD}$ reduces $\mathrm{mEPSC}$ amplitude onto L2/3 pyramidal neurons. Interestingly, although mEPSC amplitude in both V1m and V1b decreased with a similar time course following $\mathrm{MD}$, the induction mechanisms of this depression were different. Whereas uniform deprivation depressed mEPSC amplitude in V1m, in V1b only a manipulation (MD) that left ipsilateral visual drive intact was effective. This is consistent with an earlier study showing that brief BD does not reduce visual responsiveness in L4 V1b (Frenkel and Bear, 2004). Similar differences between V1m and V1b have been observed for the induction of intrinsic plasticity in layer 5 (Nataraj and Turrigiano, 2011), suggesting that for several forms of plasticity, the induction rules within V1m and V1b differ significantly.

Several forms of LTD are dependent on GluA2 C-tail interactions (Chung et al., 2003; Malenka and Bear, 2004; Steinberg et al., 2006; Yoon et al., 2009), but the dependence of L2/3 plasticity on GluA2 has not been assessed. Here we found that mEPSC

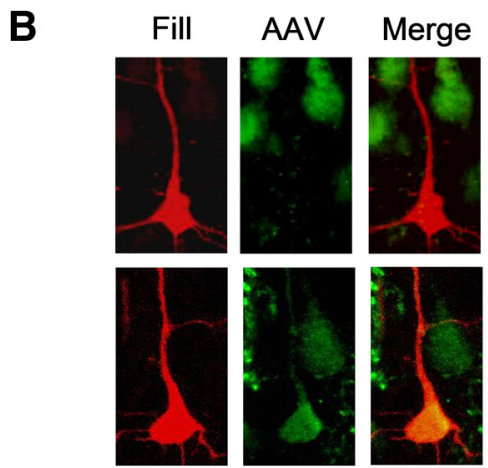

D
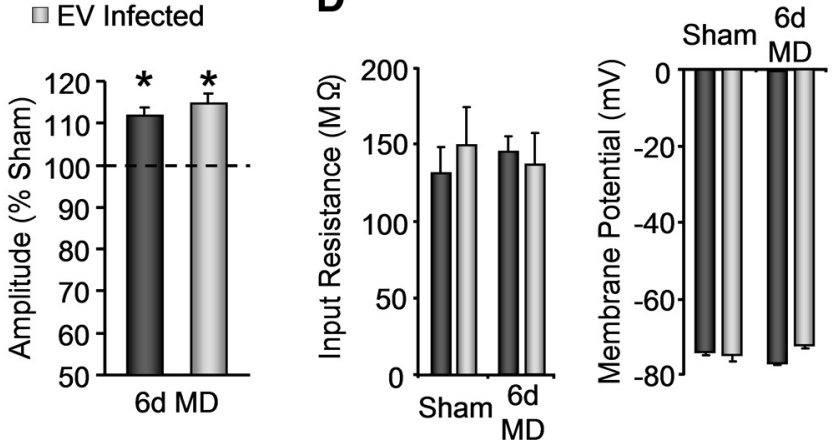

Figure 7. AAV infection with an empty vector expressing only GFP does not affect mEPSC properties. $\boldsymbol{A}$, Representative AAV uninfected and infected control conditions (left) and for uninfected and infected deprived conditions expressed as percentage of control (right) after $6 \mathrm{~d}$ MD. D, Average values for input resistance and resting membrane potential after $6 \mathrm{~d}$ MD.

depression within L2/3 was blocked in a cell-autonomous manner by viral infection with the GluA2 C-tail, consistent with the induction of a GluA2-dependent form of LTD at excitatory synapses onto L2/3 pyramidal neurons. Depression of unitary L2/3 connections was consistent with a combined presynaptic and postsynaptic mechanism and was larger in amplitude than the change in mEPSC amplitude observed here and previously (Maffei and Turrigiano, 2008), suggesting that both presynaptic and postsynaptic mechanisms contribute to MD-induced LTD within L2/3.

Although various forms of LTP can be induced at visual cortical synapses (Nelson and Turrigiano, 2008; Smith et al., 2009), the evidence that classical synapse-specific LTP underlies the second, potentiation phase of OD plasticity has largely rested on the ability to block OD shifts with NMDAR antagonists (Bear et al., 1990; Daw et al., 1999; Sawtell et al., 2003). On the other hand, several features of the potentiation phase of OD plasticity within L2/3 are more consistent with a global homeostatic mechanism. First, like synaptic scaling and unlike LTP, the potentiation phase of OD plasticity is dependent upon TNF $\alpha$ signaling (Kaneko et al., 2008). Second, the potentiation does not require spared-eye inputs, but can be induced in $\mathrm{L} 2 / 3 \mathrm{~V} 1 \mathrm{~b}$ by both MD and $\mathrm{BD}$ (Mrsic-Flogel et al., 2007). This is inconsistent with either a classical LTP-like process, or a sliding-threshold metaplasticity model, both of which will only lead to potentiation of inputs with intact correlated visual drive (Bear, 1995; Abbott and Nelson, 2000).

Here we show for the first time that postsynaptic strength is scaled up by prolonged MD with lid suture. Further, although LTP does not rely on GluA2-dependent trafficking mechanisms 


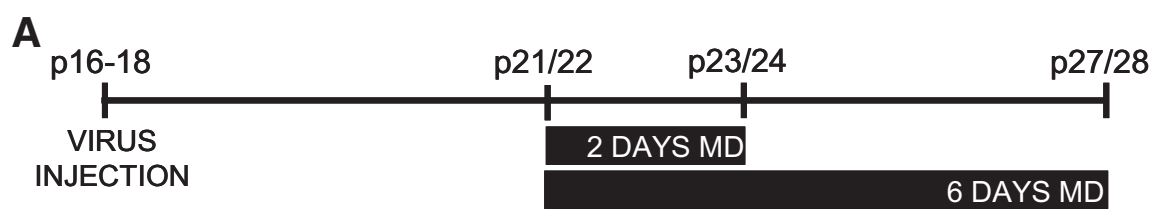

B
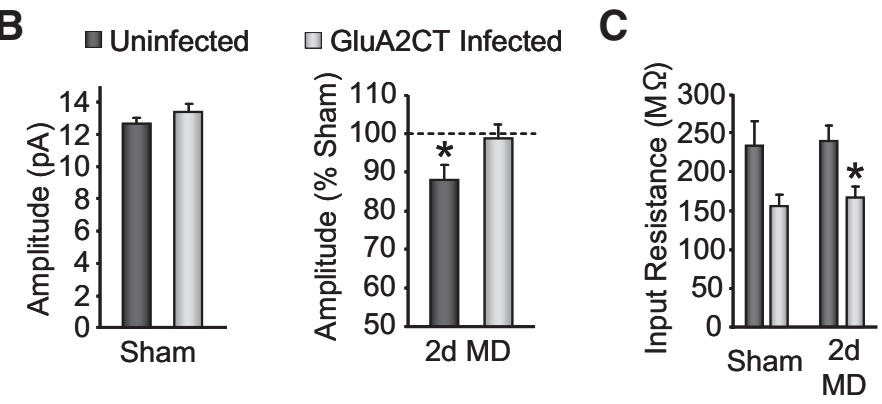

D
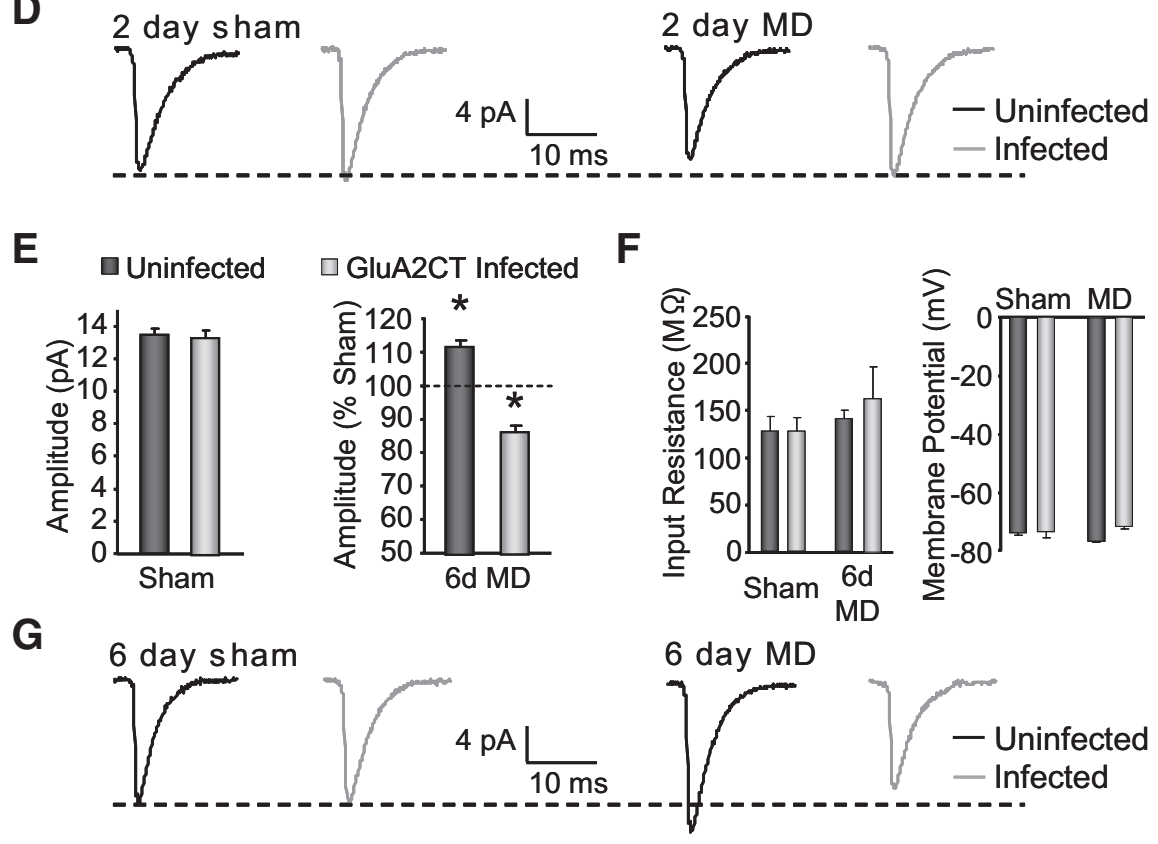

Figure 8. AAV infection with the GluA2 C-tail blocks changes in postsynaptic strength in V1b. $\boldsymbol{A}$, Timeline of virus injection and visual deprivation paradigm. $\boldsymbol{B}$, Average mEPSC amplitude for uninfected and infected sham conditions (left) and for uninfected and infected contra conditions expressed as a percentage of sham (right) after $2 \mathrm{~d}$ MD. C, Average values for input resistance and resting membrane potential after $2 \mathrm{~d}$ MD. D, Average mEPSCs for all conditions at $2 \mathrm{~d}$. E-G, Same as $\boldsymbol{B}-\boldsymbol{D}$, but data are after $6 \mathrm{~d}$ MD.

(Mainen et al., 1998; Malinow and Malenka, 2002; Gainey et al., 2009; Granger et al., 2013), synaptic scaling does (Gainey et al., 2009; Goold and Nicoll, 2010; Anggono et al., 2011), and here we show that the MD-induced increase in mEPSC amplitude is GluA2-dependent. Finally, mEPSC amplitude also increases after $\mathrm{BD}$, as predicted if the underlying mechanism is synaptic scaling rather than homosynaptic LTP. One issue with this interpretation is that if the potentiation is dependent on the preceding depression, then block of potentiation by the GluA2 C-tail may simply be a consequence of blocking depression. This interpretation seems unlikely, however, because BD does not induce depression in V1b, but still induces a delayed potentiation, indicating that potentiation can occur without a preceding depression at these synapses. Together, our data strongly support the hypothesis that synaptic scaling up of excitatory synapses is necessary for the second, potentiation phase of synaptic plasticity within L2/3. Our data cannot, however, exclude the possibility that synaptic scaling

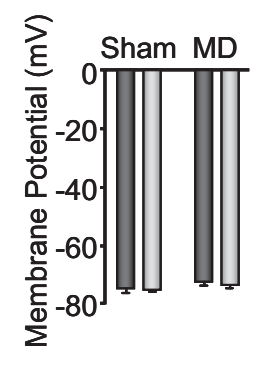

enables subsequent LTP, and so although necessary is not sufficient to fully account for the synaptic potentiation.

Interestingly, prolonged $\mathrm{BD}$ induced a smaller increase in mEPSC amplitude than MD (a similar effect was observed for MD-induced changes in visual responsiveness) (Mrsic-Flogel et al., 2007). On the face of it this seems paradoxical, because if $\mathrm{BD}$ reduces visual drive to a greater extent than MD it should induce a larger homeostatic response. However, this assumption may be incorrect. Even complete visual deprivation has only a small initial effect on thalamic and visual cortical firing rates (Fiser et al., 2004; Linden et al., 2009), so the immediate drop in activity induced by monocular and binocular lid suture is likely small and similar in magnitude. What is different between the two conditions is the induction of synaptic depression: whereas $2 \mathrm{~d}$ of MD depresses mEPSC amplitude $2 \mathrm{~d}$ of BD does not, and LTD is similarly induced only by MD (Blais et al., 2008; Smith et al., 2009). This suggests that MD may suppress cortical activity more than BD by inducing greater synaptic depression, and thus induce a correspondingly larger homeostatic compensation.

An important question is what the functional impact of the changes in mEPSC amplitude we observe might be. For example, these changes (on order of $10 \%$ depression followed by a $20 \%$ potentiation) are small relative to changes in visual drive that have been measured using visual evoked potentials in L4 (on order 50-100\%) (Frenkel and Bear, 2004). Visual evoked potentials are not a direct readout of excitatory synaptic drive, but reflect the synergistic impact of a number of changes within the L4 microcircuit that include changes in both excitation and inhibition (Huang et al., 1999; Sawtell et al., 2003; Maffei et al., 2006, 2010). It is similarly difficult to infer the magnitude of change in excitatory synaptic drive needed to account for changes in visual drive in L2/3 observed with calcium imaging (Mrsic-Flogel et al., 2007; Kaneko et al., 2008). Further, changes in visual drive to L2/3 pyramidal neurons likely reflect changes happening at many sites within the neocortical microcircuit, including changes in L4 (the primary input layer of cortex). Our data suggest that within L2/3 synaptic and intrinsic homeostatic mechanisms cooperate to enhance excitability following prolonged MD. The enhancement in intrinsic excitability we observe between 3 and $6 \mathrm{~d}$ MD should serve to amplify the changes in excitatory synaptic drive, so that together these two mechanisms could have a significant impact on visual drive.

Our data support a model for OD shifts within L2/3 in which rapid homosynaptic LTD is followed by a compensatory global scaling up of excitatory synapses. In this model, the initial depression shifts the relative strength of drive from the 
two eyes, and this difference is then maintained during scaling up. This is consistent with the observation that OD shifts peak in amplitude within the first few days of MD, and then remain relatively constant thereafter (Gordon and Stryker, 1996; Frenkel and Bear, 2004). However, our data also suggest that these changes in excitatory transmission are not the sole contributors to OD shifts within L2/3. Neocortical microcircuits possess many synaptic and intrinsic plasticity mechanisms expressed in a layer and cell-type specific manner (Nelson and Turrigiano, 2008). Our data establish that, even when considering only L2/3 pyramidal neurons, MD sets in motion a complex set of synaptic and intrinsic changes that likely cooperate to regulate visual drive to these neurons. These include a rapid postsynaptic depression, a slower postsynaptic potentiation, and a slow increase in intrinsic excitability. OD shifts in L2/3 neurons thus reflect the summed impact of multiple forms of synaptic and intrinsic plasticity that are dynamically engaged during MD.

\section{References}

Abbott LF, Nelson SB (2000) Synaptic plasticity: taming the beast. Nat Neurosci 3:1178-1183. CrossRef Medline

Anggono V, Clem RL, Huganir RL (2011) PICK1 loss of function occludes homeostatic synaptic scaling. J Neurosci 31:2188-2196. CrossRef Medline

Antonini A, Fagiolini M, Stryker MP (1999) Anatomical correlates of functional plasticity in mouse visual cortex. J Neurosci 19:4388-4406. Medline

Bear MF (1995) Mechanism for a sliding synaptic modification threshold. Neuron 15:1-4. CrossRef Medline

Bear MF, Kleinschmidt A, Gu QA, Singer W (1990) Disruption of experience-dependent synaptic modifications in striate cortex by infusion of an NMDA receptor antagonist. J Neurosci 10:909-925. Medline

Blais BS, Frenkel MY, Kuindersma SR, Muhammad R, Shouval HZ, Cooper LN, Bear MF (2008) Recovery from monocular deprivation using binocular deprivation. J Neurophysiol 100:2217-2224. CrossRef Medline

Blasdel G, Pettigrew J (1978) Effect of prior visual experience on cortical recovery from the effects of unilateral eyelid suture in kittens. Brain Res 274:601-619. Medline

Cang J, Kalatsky VA, Löwel S, Stryker MP (2005) Optical imaging of the intrinsic signal as a measure of cortical plasticity in the mouse. Vis Neurosci 22:685-691. CrossRef Medline

Chung HJ, Steinberg JP, Huganir RL, Linden DJ (2003) Requirement of AMPA receptor GluR2 phosphorylation for cerebellar long-term depression. Science 300:1751-1755. CrossRef Medline

Crozier RA, Wang Y, Liu CH, Bear MF (2007) Deprivation-induced synaptic depression by distinct mechanisms in different layers of mouse visual cortex. Proc Natl Acad Sci U S A 104:1383-1388. CrossRef Medline

Daw NW, Gordon B, Fox KD, Flavin HJ, Kirsch JD, Beaver CJ, Ji Q, Reid SN, Czepita D (1999) Injection of MK-801 affects ocular dominance shifts more than visual activity. J Neurophysiol 81:204-215. Medline

Desai NS, Rutherford LC, Turrigiano GG (1999) Plasticity in the intrinsic excitability of cortical pyramidal neurons. Nat Neurosci 2:515-520. CrossRef Medline

Desai NS, Cudmore RH, Nelson SB, Turrigiano GG (2002) Critical periods for experience-dependent synaptic scaling in visual cortex. Nat Neurosci 5:783-789. CrossRef Medline

Dräger UC (1978) Observations on monocular deprivation in mice. J Neurophysiol 41:28-42. Medline

Fiser J, Chiu C, Weliky M (2004) Small modulation of ongoing cortical dynamics by sensory input during natural vision. Nature 431:573578. CrossRef Medline

Frenkel MY, Bear MF (2004) How monocular deprivation shifts ocular dominance in visual cortex of young mice. Neuron 44:917-923. CrossRef Medline

Gainey MA, Hurvitz-Wolff JR, Lambo ME, Turrigiano GG (2009) Synaptic scaling requires the GluR2 subunit of the AMPA receptor. J Neurosci 29:6479-6489. CrossRef Medline

Goel A, Lee HK (2007) Persistence of experience-induced homeostatic syn- aptic plasticity through adulthood in superficial layers of mouse visual cortex. J Neurosci 27:6692-6700. CrossRef Medline

Goold CP, Nicoll RA (2010) Single-cell optogenetic excitation drives homeostatic synaptic depression. Neuron 68:512-528. CrossRef Medline

Gordon JA, Stryker MP (1996) Experience-dependent plasticity of binocular responses in the primary visual cortex of the mouse. J Neurosci 16: 3274-3286. Medline

Granger AJ, Shi Y, Lu W, Cerpas M, Nicoll RA (2013) LTP requires a reserve pool of glutamate receptors independent of subunit type. Nature 7433: 495-500. CrossRef Medline

Huang ZJ, Kirkwood A, Pizzorusso T, Porciatti V, Morales B, Bear MF, Maffei L, Tonegawa S (1999) BDNF regulates the maturation of inhibition and the critical period of plasticity in mouse visual cortex. Cell 98:739-755. CrossRef Medline

Hubel DH, Wiesel TN (1970) The period of susceptibility to the physiological effects of unilateral eye closure in kittens. J Physiol 206:419436. Medline

Jia Z, Agopyan N, Miu P, Xiong Z, Henderson J, Gerlai R, Taverna FA, Velumian A, MacDonald J, Carlen P, Abramow-Newerly W, Roder J (1996) Enhanced LTP in mice deficient in the AMPA receptor GluR2. Neuron 17:945-956. CrossRef Medline

Kaneko M, Stellwagen D, Malenka RC, Stryker MP (2008) Tumor necrosis factor-alpha mediates one component of competitive, experiencedependent plasticity in developing visual cortex. Neuron 58:673680. CrossRef Medline

Lee SH, Liu L, Wang YT, Sheng M (2002) Clathrin adaptor AP2 and NSF interact with overlapping sites of GluR2 and play distinct roles in AMPA receptor trafficking and hippocampal LTD. Neuron 36:661-674. CrossRef Medline

Linden ML, Heynen AJ, Haslinger RH, Bear MF (2009) Thalamic activity that drives visual cortical plasticity. Nat Neurosci 12:390-392. CrossRef Medline

Maffei A, Turrigiano GG (2008) Multiple modes of network homeostasis in visual cortical layer 2/3. J Neurosci 28:4377-4384. CrossRef Medline

Maffei A, Nelson SB, Turrigiano GG (2004) Selective reconfiguration of layer 4 visual cortical circuitry by visual deprivation. Nat Neurosci 7:1353-1359. CrossRef Medline

Maffei A, Nataraj K, Nelson SB, Turrigiano GG (2006) Potentiation of cortical inhibition by visual deprivation. Nature 443:81-84. CrossRef Medline

Maffei A, Lambo ME, Turrigiano GG (2010) Critical period for inhibitory plasticity in rodent binocular V1. J Neurosci 30:3304-3309. CrossRef Medline

Mainen ZF, Jia Z, Roder J, Malinow R (1998) Use-dependent AMPA receptor block in mice lacking GluR2 suggests postsynaptic site for LTP expression. Nat Neurosci 1:579-586. CrossRef Medline

Malenka RC, Bear MF (2004) LTP and LTD: an embarrassment of riches. Neuron 44:5-21. CrossRef Medline

Malinow R, Malenka RC (2002) AMPA receptor trafficking and synaptic plasticity. Annu Rev Neurosci 25:103-126. CrossRef Medline

Marder E, Goaillard JM (2006) Variability, compensation and homeostasis in neuron and network function. Nat Rev Neurosci 7:563-574. CrossRef Medline

Mioche L, Singer W (1989) Chronic recordings from single sites of kitten striate cortex during experience-dependent modifications of receptivefield properties. J Neurophysiol 62:185-197. Medline

Mrsic-Flogel TD, Hofer SB, Ohki K, Reid RC, Bonhoeffer T, Hübener M (2007) Homeostatic regulation of eye-specific responses in visual cortex during ocular dominance plasticity. Neuron 54:961-972. CrossRef Medline

Nataraj K, Turrigiano G (2011) Regional and temporal specificity of intrinsic plasticity mechanisms is rodent primary visual cortex. J Neurosci 31 : 17932-17940. CrossRef Medline

Nelson SB, Turrigiano GG (2008) Strength through diversity. Neuron 60: 447-482. CrossRef Medline

O’Brien RJ, Kamboj S, Ehlers MD, Rosen KR, Fischbach GD, Huganir RL (1998) Activity-dependent modulation of synaptic AMPA receptor accumulation. Neuron 21:1067-1078. CrossRef Medline

Rall W, Segev I. (1985) Space-clamp problems when voltage-clamping branched neurons with intracellular microelectrodes. In: Voltage and patch-clamping with microelectrodes (Smith TG Jr, Lecar H, Redman SJ, eds), pp 191-215. Bethesda, MD: Am Physiol Soc. 
Ramoa AS, Paradiso MA, Freeman RD (1988) Blockade of intracortical inhibition in kitten striate cortex: effects on receptive field properties and associated loss of ocular dominance plasticity. Exp Brain Res 73: 285-296. Medline

Sawtell NB, Frenkel MY, Philpot BD, Nakazawa K, Tonegawa S, Bear MF (2003) NMDA receptor-dependent ocular dominance plasticity in adult visual cortex. Neuron 38:977-985. CrossRef Medline

Sillito AM, Kemp JA, Patel H (1980) Inhibitory interactions contributing to the ocular dominance of monocularly dominated cells in the normal cat striate cortex. Exp Brain Res 41:1-10. Medline

Smith GB, Heynen AJ, Bear MF (2009) Bidirectional synaptic mechanisms of ocular dominance plasticity in visual cortex. Philos Trans R Soc Lond B Biol Sci 364:357-367. CrossRef Medline

Spruston N, Jaffe DB, Williams SH, Johnston D (1993) Voltage- and spaceclamp errors associated with the measurement of electrotonically remote synaptic events. J Neurophysiol 70:781-802. Medline

Steinberg JP, Takamiya K, Shen Y, Xia J, Rubio ME, Yu S, Jin W, Thomas GM, Linden DJ, Huganir RL (2006) Targeted in vivo mutations of the AMPA receptor subunit GluR2 and its interacting protein PICK1 eliminate cerebellar long-term depression. Neuron 49:845-860. CrossRef Medline
Steinmetz CC, Turrigiano GG (2010) Tumor necrosis factor- $\alpha$ signaling maintains the ability of cortical synapses to express synaptic scaling. J Neurosci 30:14685-14690. CrossRef Medline

Stellwagen D, Malenka RC (2006) Synaptic scaling mediated by glial TNFalpha. Nature 440:1054-1059. CrossRef Medline

Turrigiano GG, Nelson SB (2004) Homeostatic plasticity in the developing nervous system. Nat Rev Neurosci 5:97-107. CrossRef Medline

Turrigiano GG, Leslie KR, Desai NS, Rutherford LC, Nelson SB (1998) Activity-dependent scaling of quantal amplitude in neocortical neurons. Nature 391:892-896. CrossRef Medline

Turrigiano G, Abbott LF, Marder E (1994) Activity-dependent changes in the intrinsic properties of cultured neurons. Science 264:974977. CrossRef Medline

Wierenga CJ, Ibata K, Turrigiano GG (2005) Postsynaptic expression of homeostatic plasticity at neocortical synapses. J Neurosci 25:28952905. CrossRef Medline

Yoon BJ, Smith GB, Heynen AJ, Neve RL, Bear MF (2009) Essential role for a long-term depression mechanism in ocular dominance plasticity. Proc Natl Acad Sci U S A 106:9860-9865. CrossRef Medline 